\title{
Requerimento de água para irrigação do milho em Santa Catarina durante eventos La Niña
}

\author{
${\text { Rosandro B. Minuzzi }{ }^{1} \& \text { André Jr. Ribeiro }}^{1}$
}

\section{RESU MO}

A irrigação fornece um importante grau de estabilidade para a produção de alimentos desde que 0 planejamento de irrigação seja bem elaborado. Estando o fenômeno climático La N iña associado às maiores ocorrências de secas no Sul do Brasil, este estudo teve como objetivo analisar o requerimento de água para a irrigação do milho (Zea mays L.) cultivado em Santa Catarina, durante eventos de La Niña. Dados diários de sete estações meteorológicas foram utilizados para determinar o requerimento de água para irrigação (evapotranspiração da cultura - precipitação efetiva) durante o ciclo e a fase fenológica de maior necessidade hídrica da cultura e a irrigação líquida total para o ciclo do milho em três datas de semeadura, com auxílio do software CROPW AT 8.0, para anos neutros e de La Niña, observados de 1978 a 2011. Durante anos de La N iña o requerimento de água para irrigação do milho diminui à medida em que as semeaduras são tardadas. 0 O este é a região do Estado onde o requerimento de irrigação é maior ocorrendo o oposto no município de Major Vieira.

Palavras-chave: produtividade, variabilidade climática interanual, Zea mays L.

\section{Irrigation water requeriment of maize in Santa Catarina during La Niña events}

\begin{abstract}
Irrigation provides an important degree of stability for the food production if the irrigation planning is well prepared. With the climatic phenomenon La Niña associated with higher occurrences of drought in Southern Brazil, this study aimed to examine the irrigation water requeriment of maize (Zea mays L.) in Santa Catarina State, during La N iña events. D aily data from seven meteorological stations were used to determine the irrigation water requeriment (crop evapotranspiration - effective precipitation) during the cycle and phenological phase of higher crop water requeriment and net irrigation for the maize cycle for three sowing dates, using the software CRO PW AT 8.0 for neutral and La Niña years, observed from 1978 to 2011. During La Niña years, the irrigation water requeriment of maize, decrease as the sowings are delayed. The west is the region of the State where the irrigation requeriment is higher, the opposite occurring in the Major Vieira municipality.
\end{abstract}

Key words: yield, interanual climatic variability, Zea mays L. 


\section{INTRODUÇÃO}

As ocorrências de fenômenos climáticos têm sido associadas a variações nos rendimentos agrícolas de várias regiões do mundo (Hill et al., 1998; Legler et al., 1999). Dentre os fenômenos climáticos de maior interesse para o Brasil está o El Niño Oscilação Sul (ENOS) de ocorrência no oceano Pacífico Equatorial.

A variação irregular que ocorre em torno das condições normais nas componentes oceânica (El Niño) e atmosférica (Oscilação Sul) da região, revela duas fases opostas do fenômeno, sendo um desses extremos representado pelas condições de La Niña (LN), quando ocorre um resfriamento das águas superficiais e aumento na pressão atmosférica (fase fria ou fase positiva) na região leste do Pacífico Equatorial (Phillips et al., 1998).

Os efeitos no clima mais conhecidos e de maior impacto provocado pelo ENOS, estão relacionados ao regime térmico e, principalmente, o pluviométrico. No Sul do Brasil eventos da LN estão associados ao aumento nas ocorrências de seca (Findell \& Delworth, 2010; Grimm, 2009).

Cruz \& Minuzzi (2009) especificam que no Oeste de Santa Catarina as chuvas registradas em eventos LN de moderada e forte intensidade, geralmente ficam abaixo da média no bimestre outubro/novembro e assim como Cardoso \& Dias (2004), mostram que a precipitação neste período está estatisticamente correlacionada com a temperatura da superfície do mar (TSM) do Pacífico. Esses meses com desvios negativos de precipitação coincidem com os períodos mais críticos das culturas da safra primavera-verão por estarem em pleno desenvolvimento culminando com alta demanda evaporativa da atmosfera e, portanto, alto consumo de água e máxima sensibilidade ao déficit hídrico.

No Brasil, a cultura do milho (Zea mays L.) apresenta grande dispersão geográfica, por ser produzido em grande parte do território nacional. O estado de Santa Catarina se situa como o quarto maior produtor da cultura no cenário nacional (CONAB, 2011).

Considerando o coeficiente de cultura $(\mathrm{Kc})$ como parâmetro de comparação, o milho está entre as culturas de maior consumo diário de água. É provável ser este o motivo pelo qual Bergamaschi \& Matzenauer (2009) acrescentam que, em geral, as condições hídricas são as que mais afetam a produção do milho, citando as reduções nas safras de 1995/96, 1996/97, 1998/ 99, 1999/00 e 2004/05, em consequência das secas. Casualidades à parte notou-se, em três dessas situações, ocorrência da LN. No Rio Grande do Sul (RS) Berlato et al. (2005) mostraram que eventos de LN estão associados às baixas produtividades do milho.

Neste contexto, a irrigação provê um importante grau de estabilidade para a produção de alimentos visto que os efeitos das estiagens são suprimidos desde que o planejamento de irrigação seja bem elaborado. Fang et al. (2010) mostraram, utilizando um modelo calibrado para o Norte da China, que o planejamento de irrigação baseado nas respostas do trigo e milho ao déficit hídrico em diferentes fases fenológicas pode melhorar a eficiência do uso de água das plantas.
Bergonci et al. (2001) relataram aumento na eficiência de uso da água do milho se a irrigação for feita somente no período crítico, com doses de rega entre 60 e $80 \%$ daquela necessária para elevar a umidade do solo à capacidade de campo, ou seja, reduzindo os custos da produção.

Com dados coletadas em 10 anos de experimento a campo no município de Eldorado do Sul, no RS, Bergamaschi et al. (2006) concluíram que a irrigação máxima proporcionou aumento próximo a $70 \%$ no rendimento de grãos de milho, em relação à cultura não irrigada.

O custo cada vez maior de energia de bombeamento e a limitação dos recursos hídricos têm levado à busca de alternativas que racionalizem o manejo da água, visando à redução nos custos da irrigação. Ademais, é de consenso que o êxito de um investimento agrícola depende diretamente do conhecimento de fenômenos climáticos e de seus efeitos nas variáveis meteorológicas. O estudo de Adams et al. (2003) é um exemplo aplicado no México que mostra a importância em entender os efeitos do ENOS e os benefícios que a previsão do fenômeno climático traz para a agricultura do país.

As consequências do déficit hídrico nas plantas exigem um estudo minucioso tendo em vista que o impacto na produtividade de dada cultura depende da regularidade das chuvas, além das próprias características fisiológicas do vegetal.

Assim e com base em tais questionamentos, este estudo objetivou a avaliação do requerimento de irrigação do milho cultivado em Santa Catarina, durante anos do fenômeno climático La Niña.

\section{Material e MÉTODOS}

Utilizaram-se dados diários de precipitação, umidade relativa do ar, velocidade do vento, insolação, temperaturas mínima, máxima e média do ar, de sete estações meteorológicas localizadas no estado de Santa Catarina (Figura 1) pertencentes ao Instituto Nacional de Meteorologia (INMET) e à Empresa de Pesquisa Agropecuária e Extensão Rural de Santa Catarina (EPAGRI).

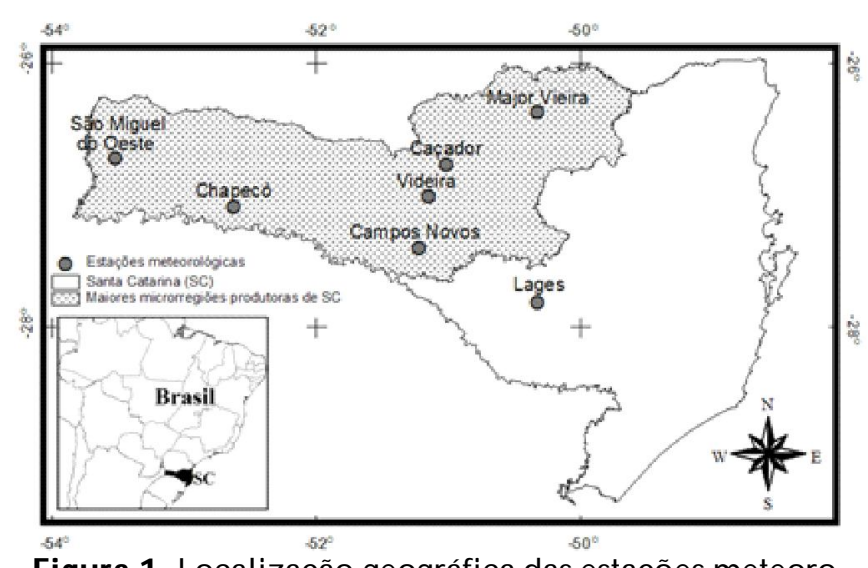

Figura 1. Localização geográfica das estações meteorológicas em seus respectivos municípios de Santa Catarina e as microrregiões que contabilizaram de 2003 a 2009 em média $80 \%$ da produção de milho do Estado (IBGE, 2011) 
Para o cálculo do requerimento de água de irrigação (evapotranspiração da cultura $(\mathrm{ETc})$ - precipitação efetiva $\left(\mathrm{P}_{\mathrm{ef}}\right)$ ) durante o ciclo e a fase fenológica de maior necessidade hídrica da cultura e a irrigação líquida total para o ciclo, foi utilizado o software CROPWAT 8.0 para cada ano neutro (AN) e de evento La Niña (LN) ocorridos no período de 1978 a 2011. Os anos de eventoLN (1984/85, 1988/89, 1995/96, 1998/99, 1999/00, 2000/ 01, 2007/08, 2010/11) foram definidos de acordo com os valores do Índice Niño Oceânico (INO) utilizado pela NOAA (National Oceanic and Atmospheric Administration). O INO foi obtido pela temperatura superficial da região Niño $3.4\left(5^{\circ} \mathrm{N}-5^{\circ} \mathrm{S}\right.$ e $\left.170^{\circ} \mathrm{W}-120^{\circ} \mathrm{W}\right)$, e a NOAA define como ocorrência de $\mathrm{LN}$, quando o INO fica abaixo de $0,5{ }^{\circ} \mathrm{C}$ por pelo menos cinco trimestres seguidos. Já para AN (1978/79, 1979/80, 1980/81, 1981/ 82, 1983/84, 1985/86, 1989/90, 1990/91, 1992/93, 1993/94, 1996/ 97, 2001/02, 2003/04, 2005/06, 2008/09), considerou-se aquele em que não houve ocorrência das duas fases do El Niño Oscilação Sul (El Niño e La Niña). Foram analisados apenas os anos em que não houve falhas nas séries de dados meteorológicos.

Para determinação da irrigação líquida durante todo o ciclo de cultivo do milho, adotaram-se os seguintes critérios quanto ao planejamento da irrigação: 1) irrigar quando a água facilmente disponível (AFD) estiver próxima a zero, ou seja, quando o conteúdo de umidade no solo se aproximar do nível no qual a planta ainda pode extrair água do solo sem passar por déficit hídrico e 2) durante cada irrigação aplicar uma lâmina de água variável o suficiente para atingir a capacidade de campo do solo.

A seguir, constam as principais informações exigidas no CROPWAT 8.0 e estabelecidas para este estudo, no que tange aos parâmetros meteorológicos, fenológicos da cultura e edafológicos:

1) Evapotranspiração de referência (ETo) - estimada pelo método de Penman-Monteith (Padrão FAO-1998), sendo a radiação solar estimada com os dados de insolação. Na ausência de dados da temperatura média do ar, umidade relativa do ar, velocidade do vento e/ou insolação, a ETo foi estimada utilizando-se apenas dados das temperaturas mínima e máxima do ar;

2) Precipitação efetiva $\left(\mathrm{P}_{\mathrm{ef}}\right)$ - obtida pelo método proposto pelo USDA Soil Conservation Service (USDA-SCS). Este método foi desenvolvido por meio de balanços hídricos relacionando-se a entrada de precipitação com as saídas por escoamento superficial e percolação, bem como a água retida na zona radicular, para várias culturas. Assim, as fórmulas obtidas estão descritas nas Eqs. 1 e 2.

$$
\begin{gathered}
\mathrm{P}_{\mathrm{ef}}=\frac{\mathrm{P}_{\text {total }}\left(125-0,2 \mathrm{P}_{\text {total }}\right)}{125}, \text { para } \mathrm{P}_{\text {total }}<250 \mathrm{~mm} \\
\mathrm{P}_{\mathrm{ef}}=125+0,1 \mathrm{P}_{\text {total }}, \text { para } \mathrm{P}_{\text {total }}>250 \mathrm{~mm}
\end{gathered}
$$

Foram consideradas três datas de semeadura: 10 de setembro, 10 de outubro e 10 de novembro. Os dados fenológicos para o milho exigidos no CROPWAT, constam na Tabela 1.

Para os dados edafológicos foram consideradas as características do solo predominante em cada local em que estão localizadas as
Tabela 1. Características da cultura do milho para as fases fenológicas inicial (I), de desenvolvimento vegetativo

\begin{tabular}{|c|c|c|c|c|c|}
\hline & \multicolumn{4}{|c|}{ Fases fenológicas } & \multirow{2}{*}{ Ciclo } \\
\hline & $I$ & DV & IM & $M$ & \\
\hline Coeficiente de cultura (Kc) & 0,45 & - & 1,20 & 0,70 & 0,80 \\
\hline $\begin{array}{l}\text { Duração das fases } \\
\text { fenológicas (dias) }\end{array}$ & 20 & 35 & 70 & 15 & 140 \\
\hline $\begin{array}{l}\text { Profundidade efetiva } \\
\text { radicular }(\mathrm{m})\end{array}$ & 0,30 & - & 0,50 & - & - \\
\hline $\begin{array}{l}\text { Fração de esgotamento } \\
\text { crítico de água no solo }\end{array}$ & 0,55 & - & 0,55 & 0,70 & - \\
\hline
\end{tabular}
(DV), intermediária (IM) e de maturação (M)

Fontes: Matzenauer et al. (1998), Doorenbos \& Kassaam (2000), Marouelli et al. (2008)

estações meteorológicas, classificando-os em três grupos de acordo com a textura: Tipo 1 - Solos de textura arenosa (baixo armazenamento); Tipo 2 - Solos de textura média (médio armazenamento) e Tipo 3 - Solos de textura argilosa (armazenamento elevado). Para todos os tipos de solo foram consideradas a profundidademáxima radicular para omilho de $100 \mathrm{~cm}$ e a deficiência de umidade do solo no momento da semeadura de $20 \%$ em relação à capacidade de água disponível (CAD). A Tabela 2 apresenta as demais informações para cada um dos referidos tipos de solo.

Tabela 2. D ados edafológicos para os três tipos de solo (arenoso, médio, argiloso) de acordo com a textura

\begin{tabular}{lrrr}
\hline & \multicolumn{4}{c}{ Tipo de solo $^{*}$} \\
\cline { 2 - 4 } Capacidade de água disponível (CAD) $\left(\mathrm{mm} \mathrm{m}^{-1}\right)$ & $\mathbf{1}$ & $\mathbf{2}$ & $\mathbf{3}$ \\
Taxa de infiltração máxima da chuva $\left(\mathrm{mm} \mathrm{d}^{-1}\right)$ & 40 & 140 & 200 \\
\hline
\end{tabular}

Fontes: Doorenbos \& Kassam (2000); Marouelli et al. (2008)

1 - textura arenosa, 2 - textura média, 3 - textura argilosa

O teste t de Student (Eq. 3) foi utilizado para averiguar a significância estatística a nível de 5\% na diferença entre as médias do requerimento de água para irrigação obtida de todos anos LN e de AN para cada estação meteorológica.

$$
\mathrm{t}_{\mathrm{n}_{1}+\mathrm{n}_{2}-2}=\frac{\overline{\mathrm{x}}_{1}-\overline{\mathrm{x}}_{2}}{\sqrt{\mathrm{s}_{\mathrm{p}}^{2}\left(\frac{1}{\mathrm{n}_{1}}+\frac{1}{\mathrm{n}_{2}}\right)}}
$$

sendo:

$\mathrm{x}_{1}$ e $\mathrm{x}_{2}$ - média do requerimento de água para irrigação dos anos $\mathrm{LN}$ e $\mathrm{AN}$, respectivamente;

$\mathrm{n}_{1}$ e $\mathrm{n}_{2}$ - tamanho das amostras referente aos anos LN e AN, respectivamente;

$\mathrm{s}_{\mathrm{p}}{ }^{2}$ - variância das duas amostras (LN e AN).

\section{RESULTADOS E DISCUSSÃO}

Os resultados do requerimento de água para irrigação (RAI) baseados na diferença de ETc e $\mathrm{P}_{\text {ef }}$ (Tabela 3) mostram que Chapecó e, principalmente, São Miguel do Oeste, no Oeste do Estado, foram os municípios com maior número de La Niñas (LN) em que o RAI nas duas primeiras semeaduras analisadas foi superior à média obtida em anos neutros (AN). A diferença 
Tabela 3. Requerimento de água para irrigação $(\mathrm{mm})$ total durante todo o ciclo do milho semeado em 10 de setembro (A), 10 de outubro (B) e 10 de novembro (C) em eventos La N iña (LN) para al guns municípios de Santa Catarina e a média de todas $L N$ e anos neutros (AN)

\begin{tabular}{|c|c|c|c|c|c|c|c|c|c|c|c|}
\hline & \multirow{2}{*}{$1984 / 85$} & \multirow{2}{*}{$1988 / 89$} & \multirow{2}{*}{$1995 / 96$} & \multirow{2}{*}{$1998 / 99$} & \multirow{2}{*}{$1999 / 00$} & \multirow{2}{*}{$2000 / 01$} & \multirow{2}{*}{$2007 / 08$} & \multirow{2}{*}{$2010 / 11$} & \multicolumn{2}{|c|}{ Média } & \multirow{2}{*}{ LN-AN } \\
\hline & & & & & & & & & LN & AN & \\
\hline \multicolumn{12}{|c|}{ A. Semeadura: 10 de setembro } \\
\hline Caçador & 181,7 & 115,2 & 179,3 & 120,5 & 180,1 & 130,0 & 234,9 & - & 163,1 & 146,5 & $16,6^{\text {ns }}$ \\
\hline Campos Novos & - & 126,9 & 214,2 & 163,4 & 209,3 & 90,9 & 116,5 & 177,0 & 156,9 & 159,9 & $-3,0^{\text {ns }}$ \\
\hline Chapecó & 211,1 & 160,0 & 200,6 & 181,7 & 224,6 & 141,5 & 157,6 & 209,1 & 185,8 & 154,3 & $31,5^{\text {ns }}$ \\
\hline Lages & 161,1 & 91,1 & 135,3 & 150,0 & 144,2 & - & 64,5 & 167,6 & 130,5 & 126,6 & $3,9^{\text {ns }}$ \\
\hline Major Vieira & - & 99,2 & 93,7 & 103,1 & 121,1 & - & 197,4 & - & 122,9 & 138,7 & $-15,8^{\text {ns }}$ \\
\hline S.M. do Oeste & - & 252,5 & 266,0 & 217,8 & 268,4 & 200,9 & 186,9 & - & 232,1 & 183,5 & $48,6^{\mathrm{ns}}$ \\
\hline Videira & 161,1 & 87,1 & 109,6 & 102,9 & 169,3 & 99,1 & 103,7 & - & 119,0 & 112,5 & $6,5^{\mathrm{ns}}$ \\
\hline \multicolumn{12}{|c|}{ B. Semeadura: 10 de outubro } \\
\hline Caçador & 189,0 & 104,5 & 149,5 & 110,1 & 158,6 & 133,9 & 294,5 & - & 162,9 & 147,5 & $15,4^{\text {ns }}$ \\
\hline Campos Novos & - & 101,6 & 188,6 & 156,2 & 176,2 & 74,0 & 146,1 & 158,2 & 143,0 & 164,6 & $-21,6^{\mathrm{ns}}$ \\
\hline Chapecó & 212,5 & 121,5 & 172,3 & 170,6 & 202,7 & 104,8 & 233,1 & 165,4 & 172,9 & 172,0 & $0,9^{\text {ns }}$ \\
\hline Lages & 167,1 & 95,7 & 127,5 & 131,0 & 149,9 & - & 62,8 & 114,6 & 121,2 & 138,1 & $-16,9^{\text {ns }}$ \\
\hline Major Vieira & - & 76,7 & 80,8 & 100,7 & 105,2 & - & 275,1 & - & 127,7 & 139,8 & $-12,1^{\text {ns }}$ \\
\hline S.M. do Oeste & - & 187,6 & 243,2 & 221,6 & 273,7 & 177,4 & 280,8 & - & 230,7 & 197,7 & $33,0^{\text {ns }}$ \\
\hline Videira & 165,4 & 84,1 & 79,8 & 93,4 & 120,8 & 73,9 & 139,3 & - & 108,1 & 110,3 & $-2,2^{\text {ns }}$ \\
\hline \multicolumn{12}{|c|}{ C. Semeadura: 10 de novembro } \\
\hline Caçador & 160,7 & 62,9 & 78,3 & 134,8 & 123,0 & 166,2 & 306,8 & - & 147,5 & 136,3 & $11,2^{\text {ns }}$ \\
\hline Campos Novos & - & 76,5 & 101,9 & 173,7 & 119,5 & 93,6 & 116,8 & 153,3 & 119,3 & 152,2 & $-32,9^{\text {ns }}$ \\
\hline Chapecó & 192,3 & 76,8 & 102,9 & 166,5 & 203,0 & 81,2 & 234,8 & 181,9 & 154,9 & 170,0 & $-15,1^{\text {ns }}$ \\
\hline Lages & 147,5 & 71,9 & 90,7 & 132,5 & 127,9 & - & 37,0 & 113,1 & 102,9 & 126,1 & $-23,2^{\text {ns }}$ \\
\hline Major Vieira & - & 24,5 & 44,1 & 95,2 & - & - & 260,2 & - & 106,0 & 111,9 & $-5,9^{\text {ns }}$ \\
\hline S.M. do Oeste & - & 98,6 & 152,4 & 176,7 & 245,4 & 106,4 & 279,7 & - & 176,5 & 200,8 & $-24,3^{\text {ns }}$ \\
\hline Videira & 191,6 & 73,7 & 21,1 & 116,9 & 60,7 & 51,4 & 143,3 & - & 94,1 & 104,0 & $-9,9^{\text {ns }}$ \\
\hline
\end{tabular}

ns não-significativo

entre as médias de RAI de eventos LN e AN para o município do extremo Oeste (48,3 e $33 \mathrm{~mm}$ para semeaduras em 10 de setembro e 10 de outubro, respectivamente) ilustra esta afirmação, apesar de não serem estatisticamente diferentes.

Atente-se para o município de Caçador, que foi o único a apresentar médias de LN maior que as encontradas para AN em todas as datas de semeadura motivo que se deve aos elevados valores de RAI durante a LN 2007/08. Salvo esta exceção de Caçador, nos demais municípios a média do RAI em AN foi maior que de LN para semeaduras feitas em 10 de novembro, sugerindo que os efeitos geralmente observados no Sul do Brasil de chuvas abaixo da climatologia durante eventos LN, não são notados para o cultivo do milho semeados neste período, no que tange à demanda de água.

Na maioria dos eventos LN este comportamento das chuvas em Santa Catarina é observado no bimestre outubro/novembro (Cruz \& Minuzzi, 2009; Minuzzi, 2010), ou seja, afetando, de forma mais significativa apenas a fase inicial do milho que não é a de maior exigência de água.

Raciocínio semelhante ao destacado para Caçador também é válido para Major Vieira, em todas as datas de semeadura. Neste município ao Norte de Santa Catarina, em apenas uma LN (2007/08), o RAI foi maior que a média de AN. Ressalta-se que em razão da ausência de dados meteorológicos na série de Major Vieira, três eventos da fase fria do ENOS não puderam ser analisados, como o de 1984/85, em que RAI foi maior do que a média de AN em todos os municípios e datas de semeadura. Somado a esta LN (1984/85), nos eventos de 1999/ 00 e 2007/08 também se observou, predominantemente, maior RAI para o milho em Santa Catarina nas três datas de semeadura. Em contrapartida, 1988/89 e 2000/01 foram os anos de LN com menor RAI, mesmo o primeiro tendo sido um evento de forte intensidade.

Essas diferenças observadas nas análises individuais dos eventos LN têm, como uma das explicações, o tempo de resposta das condições oceânicas do Pacífico Equatorial nas condições atmosféricas de Santa Catarina, conforme sugerido no estudo de Kayano \& Sansigolo (2009). Os autores destacam que, em geral, o resfriamento da temperatura da superfície do mar (TSM) do Pacífico Equatorial está em fase ou antecede em até um ano, a diminuição das chuvas que são observadas no Sul do Brasil.

Os resultados do RAI (ETc- $\mathrm{P}_{\mathrm{ef}}$ ) durante a fase de maior exigência de água (Tabela 4) são visíveis em indicar que o risco de déficit hídrico para o milho, em anos de LN, torna-se maior para semeaduras feitas em 10 de setembro, principalmente no Oeste de Santa Catarina (Chapecó e São Miguel do Oeste).

Em média, as diferenças de RAI durante a fase intermediária observadas durante eventos LN, são maiores que em AN, a ponto de, em São Miguel do Oeste, esta diferença $(55,4 \mathrm{~mm})$ ser estatisticamente significativa a nível de 0,05 .

A exceção quanto ao risco de semeaduras precoces do milho (em torno de 10 de setembro) em anos LN é feita para Major Vieira, onde em apenas um evento (2007/08) o RAI para a fase intermediária $(143,3 \mathrm{~mm})$ foi maior do que em média se observa em AN (116,8 mm) no município (Tabela 4).

No contexto geral, durante eventos LN seria unânime indicar semeaduras do milho nas principais regiões produtoras de Santa Catarina em 10 de outubro e 10 de novembro, se não fossem os resultados obtidos nos eventos de 1984/85, 2007/08 
Tabela 4. Requerimento de água para irrigação $(\mathrm{mm})$ durante a fase intermediária (IM) do milho semeado em 10 de setembro (A), 10 de outubro (B) e 10 de novembro (C) em eventos La N iña (LN) para al guns municípios de Santa Catarina e a média de todas $L N$ e anos neutros (AN)

\begin{tabular}{|c|c|c|c|c|c|c|c|c|c|c|c|}
\hline & \multirow{2}{*}{$1984 / 85$} & \multirow{2}{*}{$1988 / 89$} & \multirow{2}{*}{$1995 / 96$} & \multirow{2}{*}{$1998 / 99$} & \multirow{2}{*}{$1999 / 00$} & \multirow{2}{*}{$2000 / 01$} & \multirow{2}{*}{$2007 / 08$} & \multirow{2}{*}{$2010 / 11$} & \multicolumn{2}{|c|}{ Média } & \multirow{2}{*}{ LN-AN } \\
\hline & & & & & & & & & LN & AN & \\
\hline \multicolumn{12}{|c|}{ A. Semeadura: 10 de setembro } \\
\hline Caçador & 69,4 & 113,8 & 177,7 & 119,6 & 154,1 & 86,4 & 199,4 & - & 131,5 & 117,5 & $14,0^{\text {ns }}$ \\
\hline Campos Novos & - & 125,3 & 212,2 & 162,3 & 173,3 & 89,7 & 114,8 & 149,2 & 146,7 & 132,1 & $14,6^{\text {ns }}$ \\
\hline Chapecó & 90,9 & 145,4 & 198,9 & 180,7 & 195,4 & 118,9 & 122,9 & 172,4 & 153,2 & 118,4 & $34,8^{\text {ns }}$ \\
\hline Lages & 71,7 & 79,9 & 134,0 & 135,3 & 117,5 & - & 59,1 & 141,5 & 105,6 & 91,0 & $14,6^{\mathrm{ns}}$ \\
\hline Major Vieira & - & 92,3 & 91,1 & 101,8 & 98,2 & - & 143,3 & - & 105,3 & 116,8 & $-11,5^{\mathrm{ns}}$ \\
\hline S.M. do Oeste & - & 220,7 & 257,6 & 214,0 & 239,2 & 184,8 & 132,8 & - & 208,2 & 152,8 & $55,4^{*}$ \\
\hline Videira & 80,5 & 81,2 & 108,3 & 101,9 & 135,4 & 98,1 & 90,9 & - & 99,5 & 90,9 & $8,6^{\text {ns }}$ \\
\hline \multicolumn{12}{|c|}{ B. Semeadura: 10 de outubro } \\
\hline Caçador & 114,5 & 67,3 & 100,5 & 42,6 & 111,0 & 122,8 & 201,1 & - & 108,5 & 116,2 & $-7,7^{\mathrm{ns}}$ \\
\hline Campos Novos & - & 56,6 & 115,4 & 94,4 & 103,6 & 50,9 & 86,4 & 114,8 & 88,9 & 120,1 & $-31,2^{\text {ns }}$ \\
\hline Chapecó & 164,2 & 93,3 & 95,6 & 93,9 & 114,0 & 71,9 & 152,4 & 141,4 & 115,8 & 136,8 & $-21,0^{\text {ns }}$ \\
\hline Lages & 127,4 & 75,9 & 72,6 & 70,6 & 98,1 & - & 27,4 & 109,3 & 83,0 & 102,0 & $-19,0^{\mathrm{ns}}$ \\
\hline Major Vieira & - & 33,6 & 42,9 & 56,3 & 65,1 & - & 178,6 & - & 75,3 & 106,0 & $-30,7^{\mathrm{ns}}$ \\
\hline S.M. do Oeste & - & 127,1 & 140,0 & 108,9 & 169,5 & 108,2 & 196,4 & - & 141,7 & 142,9 & $-1,2^{\text {ns }}$ \\
\hline Videira & 144,1 & 57,2 & 24,8 & 54,4 & 59,8 & 63,2 & 91,7 & - & 70,7 & 77,5 & $-6,8^{\text {ns }}$ \\
\hline \multicolumn{12}{|c|}{ C. Semeadura: 10 de novembro } \\
\hline Caçador & 111,0 & 58,7 & 41,8 & 54,3 & 40,0 & 125,7 & 205,4 & - & 91,0 & 91,5 & $-0,5^{\mathrm{ns}}$ \\
\hline Campos Novos & - & 50,7 & 26,4 & 74,9 & 49,3 & 58,1 & 77,5 & 131,5 & 66,9 & 94,0 & $-27,1^{\text {ns }}$ \\
\hline Chapecó & 158,0 & 37,5 & 28,9 & 78,7 & 93,2 & 50,0 & 169,8 & 130,8 & 93,4 & 113,3 & $-19,9^{\text {ns }}$ \\
\hline Lages & 96,2 & 62,0 & 70,5 & 61,0 & 56,4 & - & 26,4 & 94,5 & 66,7 & 84,9 & $-18,2^{\text {ns }}$ \\
\hline Major Vieira & - & 15,1 & 37,4 & 56,1 & - & - & 213,5 & - & 80,5 & 66,9 & $13,6^{\text {ns }}$ \\
\hline S.M. do Oeste & - & 39,9 & 61,7 & 92,9 & 121,1 & 91,3 & 211,6 & - & 103,1 & 122,8 & $-19,7^{\text {ns }}$ \\
\hline Videira & 136,4 & 71,7 & 5,8 & 58,3 & 29,2 & 36,5 & 112,0 & - & 64,3 & 63,0 & $1,3^{\text {ns }}$ \\
\hline
\end{tabular}

${ }^{\text {ns }}$ não-significativo; * significativo a 0,05

e 2010/11, tendo em vista que nos outros cinco eventos LN analisados, o RAI foi menor na fase intermediária do que se observa, em média, durante AN.

Tão importante quanto analisar o RAI para todo o ciclo, é detalhar esta informação para a fase crítica do milho já que, havendo um bom suprimento de água durante esta fase fenológica (seja por irrigação ou precipitação) é o suficiente para que não hajam perdas na produtividade (Bergamaschi et al., 2004; 2006; Bergamaschi \& Matzenauer, 2009).

Ao contrário do RAI obtido por ETc- $\mathrm{P}_{\text {ef }}$, a irrigação líquida considera as características do solo no seu cálculo, além dos parâmetros meteorológicos e características da cultura. Somado a isto, os valores de irrigação líquida destacados na Tabela 5 devem ser considerados aqueles que adotam os mesmos critérios para o planejamento de irrigação utilizados neste estudo.

Bergamaschi et al. (2006) indicam, porém, que lâminas de irrigação de aproximadamente $60 \%$ daquela necessária para elevar o conteúdo de umidade do solo à sua capacidade de campo, permitem aumentar a eficiência do uso de água, ou seja, os valores destacados na Tabela 5 podem ser menores se o produtor optar em alterar o critério de lâmina de irrigação em relação ao utilizado neste estudo.

Apesar dessas diferenças nas maneiras de cálculo do RAI e da lâmina líquida, os resultados são relativamente semelhantes no que tange à comparação dos valores obtidos para anos LN e AN. Por exemplo, a diminuição do RAI durante eventos LN em relação à AN, sempre que as semeaduras sejam mais tardias.

Todavia, exceções podem ocorrer como observado na LN 2007/08 e no município de Major Vieira. Neste município e independente da data de semeadura, o requerimento de irrigação líquida em anos LN, é menor que o observado em AN. Esta ressalva feita a Major Vieira só não refletiu na diferença entre as médias da LN e AN, pois o maior efeito da LN 2007/08, foi em Major Vieira, com requerimento de irrigação líquida de $258,2,362,8$ e $312,3 \mathrm{~mm}$ para as semeaduras feitas em $10 \mathrm{de}$ setembro, 10 de outubro e 10 de novembro, respectivamente.

Para o outro município do Planalto catarinense (Lages), o cenário foi mais favorável para semeaduras do milho feitas após 10 de outubro. Dentre os 14 eventos LN analisados, em apenas um (1998/99, para semeadura em 10 de novembro), o requerimento de irrigação líquida foi maior que a média de AN (Tabela 5).

Ressalta-se que o uso total de água para irrigação (bruta) é maior que os valores apresentados na Tabela 5 em virtude da irrigação bruta estar diretamente relacionada com a eficiência de aplicação da água de irrigação.

Por exemplo, como em Campos Novos a irrigação líquida para o milho em anos LN é em média de 140,3 mm para semeaduras feitas em 10 de setembro considerando-se que a eficiência da irrigação seja de 70\%, a lâmina de irrigação bruta será de 200,4 mm.

Em termos médios, na maioria dos planejamentos de irrigação a eficiência de aplicação não ultrapassa $60 \%$. Variações ao longo do ciclo vegetativo devem ser observadas ocorrendo altas eficiências durante períodos de demandas máximas e baixas no princípio e no final desses períodos (Doorenbos \& Pruitt, 1997).

$\mathrm{Na}$ ausência das irrigações líquidas para todo o ciclo (Tabela 5) as perdas na produtividade do milho estimadas pelo Cropwat durante eventos LN unicamente devido ao déficit hídrico, estão destacadas na Tabela 6. 
Tabela 5. Lâmina de irrigação líquida $(\mathrm{mm})$ total durante todo o ciclo do milho semeado em 10 de setembro (A), 10 de outubro (B) e 10 de novembro (C) em eventos La Niña (LN ) para alguns municípios de Santa Catarina e a média de todas LN e anos neutros (AN)

\begin{tabular}{|c|c|c|c|c|c|c|c|c|c|c|c|}
\hline & \multirow{2}{*}{$1984 / 85$} & \multirow{2}{*}{$1988 / 89$} & \multirow{2}{*}{$1995 / 96$} & \multirow{2}{*}{$1998 / 99$} & \multirow{2}{*}{$1999 / 00$} & \multirow{2}{*}{$2000 / 01$} & \multirow{2}{*}{$2007 / 08$} & \multirow{2}{*}{$2010 / 11$} & \multicolumn{2}{|c|}{ Média } & \multirow{2}{*}{ LN-AN } \\
\hline & & & & & & & & & LN & AN & \\
\hline \multicolumn{12}{|c|}{ A. Semeadura: 10 de setembro } \\
\hline Caçador & 113,0 & 116,0 & 233,5 & 116,0 & 113,8 & 116,1 & 175,7 & - & 140,6 & 101,0 & $39,6^{\text {ns }}$ \\
\hline Campos Novos & - & 114,6 & 229,6 & 171,2 & 175,2 & 58,6 & 60,1 & 172,6 & 140,3 & 108,4 & $31,9^{\text {ns }}$ \\
\hline Chapecó & 208,0 & 121,0 & 167,8 & 166,4 & 202,0 & 117,5 & 123,6 & 208,1 & 164,3 & 151,7 & $12,6^{\text {ns }}$ \\
\hline Lages & 164,9 & 80,0 & 164,5 & 118,5 & 159,9 & - & 41,0 & 162,0 & 127,3 & 112,5 & $14,8^{\text {ns }}$ \\
\hline Major Vieira & - & 82,8 & 81,8 & 118,1 & 81,0 & - & 258,2 & - & 124,4 & 120,4 & $4,0^{\text {ns }}$ \\
\hline S.M. do Oeste & - & 235,5 & 233,8 & 166,9 & 229,8 & 173,0 & 113,1 & - & 192,0 & 163,1 & $28,9^{\text {ns }}$ \\
\hline Videira & 114,8 & 56,2 & 112,4 & 56,4 & 169,7 & 114,1 & 116,6 & - & 105,7 & 63,8 & $41,9^{\text {ns }}$ \\
\hline \multicolumn{12}{|c|}{ B. Semeadura: 10 de outubro } \\
\hline Caçador & 99,7 & 0 & 112,6 & 115,1 & 55,3 & 110,5 & 225,3 & - & 102,6 & 129,7 & $-27,1^{\text {ns }}$ \\
\hline Campos Novos & - & 57,2 & 171,4 & 111,5 & 116,0 & 55,4 & 110,7 & 115,3 & 105,4 & 114,4 & $-9,0^{\text {ns }}$ \\
\hline Chapecó & 234,5 & 113,5 & 196,5 & 152,2 & 155,9 & 81,7 & 204,3 & 163,0 & 162,7 & 169,8 & $-7,1^{\text {ns }}$ \\
\hline Lages & 120,8 & 77,1 & 81,9 & 121,4 & 120,8 & - & 40,2 & 122,8 & 97,9 & 134,2 & $-36,3^{*}$ \\
\hline Major Vieira & - & 36,5 & 41,8 & 120,4 & 80,4 & - & 362,8 & - & 128,4 & 128,4 & $0,0^{\text {ns }}$ \\
\hline S.M. do Oeste & - & 165,7 & 217,1 & 166,0 & 227,3 & 114,4 & 229,9 & - & 186,7 & 171,5 & $15,2^{\text {ns }}$ \\
\hline Videira & 168,7 & 0 & 57,6 & 0 & 110,3 & 57,1 & 169,9 & - & 80,5 & 50,2 & $30,3^{\text {ns }}$ \\
\hline \multicolumn{12}{|c|}{ C. Semeadura: 10 de novembro } \\
\hline Caçador & 58,2 & 0 & 57,8 & 56,2 & 55,0 & 110,7 & 229,7 & - & 81,1 & 94,2 & $-13,1^{\text {ns }}$ \\
\hline Campos Novos & - & 55,2 & 47,8 & 115,1 & 54,9 & 55,3 & 55,6 & 171,7 & 79,4 & 110,3 & $-30,9^{\text {ns }}$ \\
\hline Chapecó & 204,8 & 75,5 & 67,4 & 146,9 & 186,8 & 75,0 & 248,3 & 164,1 & 146,1 & 157,9 & $-11,8^{\text {ns }}$ \\
\hline Lages & 78,8 & 41,4 & 83,0 & 153,2 & 78,6 & - & 41,2 & 79,9 & 79,4 & 118,7 & $-39,3^{\text {ns }}$ \\
\hline Major Vieira & - & 0 & 0 & 81,3 & - & - & 312,3 & - & 98,4 & 88,0 & $10,4^{\text {ns }}$ \\
\hline S.M. do Oeste & - & 47,3 & 43,8 & 160,7 & 209,7 & 55,5 & 176,0 & - & 115,5 & 161,5 & $-46,0^{\text {ns }}$ \\
\hline Videira & 174,1 & 0 & 0 & 58,3 & 0 & 0 & 112,4 & - & 49,3 & 49,7 & $-0,4^{\mathrm{ns}}$ \\
\hline
\end{tabular}

${ }^{\text {ns }}$ não-significativo; * significativo a 0,05

Tabela 6. Redução na produtividade (\%) do milho semeado em 10 de setembro (A), 10 de outubro (B) e 10 de novembro (C) em eventos La N iña (LN) para al guns municípios de Santa Catarina e respectivas médias e desvio padrões (DP) de todas LN

\begin{tabular}{|c|c|c|c|c|c|c|c|c|c|c|}
\hline & $1984 / 85$ & $1988 / 89$ & $1995 / 96$ & $1998 / 99$ & $1999 / 00$ & $2000 / 01$ & $2007 / 08$ & $2010 / 11$ & Média & DP \\
\hline \multicolumn{11}{|c|}{ A. Semeadura: 10 de setembro } \\
\hline Caçador & 6,5 & 6,9 & 23,8 & 7,3 & 21,9 & 1,8 & 22,6 & - & 13,0 & 9,4 \\
\hline Campos Novos & - & 9,6 & 32,0 & 14,5 & 26,5 & 2,9 & 7,1 & 13,7 & 15,2 & 10,5 \\
\hline Chapecó & 13,9 & 16,8 & 31,7 & 27,6 & 30,5 & 15,8 & 15,3 & 25,2 & 22,1 & 7,4 \\
\hline Lages & 3,3 & 2,5 & 15,4 & 17,1 & 16,0 & - & 3,0 & 9,2 & 9,5 & 6,6 \\
\hline Major Vieira & - & 15,6 & 2,1 & 8,9 & 9,0 & - & 12,4 & - & 9,6 & 5,0 \\
\hline S.M. do Oeste & - & 29,3 & 35,1 & 30,1 & 28,7 & 21,1 & 12,6 & - & 26,2 & 8,0 \\
\hline Videira & 10,9 & 0,7 & 11,4 & 2,8 & 17,8 & 0,5 & 0,9 & - & 6,4 & 6,9 \\
\hline \multicolumn{11}{|c|}{ B. Semeadura: 10 de outubro } \\
\hline Caçador & 8,7 & 0 & 11,7 & 0,2 & 8,5 & 9,8 & 33,6 & - & 10,4 & 11,2 \\
\hline Campos Novos & - & 0,5 & 19,1 & 6,2 & 11,1 & 0,1 & 4,9 & 7,8 & 7,1 & 6,6 \\
\hline Chapecó & 22,8 & 9,7 & 19,5 & 16,1 & 17,3 & 8,8 & 30,9 & 21,6 & 18,3 & 7,2 \\
\hline Lages & 16,3 & 0,2 & 5,2 & 9,0 & 11,4 & - & 1,2 & 5,6 & 7,0 & 5,7 \\
\hline Major Vieira & - & 3,8 & 0,1 & 1,4 & 6,9 & - & 28,8 & - & 8,2 & 11,8 \\
\hline S.M. do Oeste & - & 15,7 & 21,8 & 20,6 & 27,0 & 9,2 & 28,9 & - & 20,5 & 7,3 \\
\hline Videira & 19,2 & 0 & 1,5 & 0 & 3,9 & 0 & 2,6 & - & 3,9 & 6,9 \\
\hline \multicolumn{11}{|c|}{ C. Semeadura: 10 de novembro } \\
\hline Caçador & 5,4 & 0 & 0 & 4,5 & 1,3 & 9,7 & 35,4 & - & 8,0 & 12,6 \\
\hline Campos Novos & - & 0 & 2,9 & 3,1 & 0,9 & 0,5 & 0 & 6,2 & 1,9 & 2,3 \\
\hline Chapecó & 20,4 & 0,8 & 5,8 & 6,0 & 14,8 & 0,7 & 31,0 & 20,6 & 12,5 & 10,9 \\
\hline Lages & 14,9 & 0,5 & 2,2 & 5,3 & 6,3 & - & 0,3 & 3,5 & 4,7 & 5,0 \\
\hline Major Vieira & - & 0 & 0 & 0,1 & - & - & 31,7 & - & 8,0 & 15,8 \\
\hline S.M. do Oeste & - & 1,2 & 3 & 4,7 & 16,9 & 0 & 26,1 & - & 8,7 & 10,5 \\
\hline Videira & 15,8 & 0 & 0 & 3,1 & 0 & 0 & 8,1 & - & 3,9 & 6,1 \\
\hline
\end{tabular}

Assim, quanto maior o requerimento de irrigação líquida, maior a perda da produtividade na ausência de irrigação. Como exemplos, em média as perdas decorrentes do déficit hídrico em anos LN foram maiores nos municípios do Oeste catarinense (Chapecó e São Miguel do Oeste) e diminuem quanto mais tardia for a semeadura. Associando dados do Índice de 
Oscilação Sul (IOS) e da TSM do Pacífico Equatorial e Atlântico Sul com a produtividade de algumas culturas na principal região agrícola da Argentina (região dos Pampas), Travasso et al. (2009) reinteiraram os efeitos do ENOS na agricultura já que, para o milho, o IOS de setembro a maio foi o melhor indicador da variabilidade observada na produtividade do cereal. Com objetivos semelhantes, Kayano \& Sansigolo (2009) mostram que as chuvas no Sul do Brasil possuem maior coerência com o índice de TSM da região Niño 3.4 do que com o índice do Atlântico Subtropical Sudoeste. Acrescentam que isto deve estar relacionado com o fato de que os principais sistemas meteorológicos indutores de chuva na região se deslocam do sudoeste ao nordeste ou do oeste ao leste (frentes frias e Sistemas Convectivos de Mesoescala), indicando uma hipótese para o fato do Oeste de Santa Catarina ser a região com maior RAI durante LN e resultando em maiores perdas na produtividade da cultura.

No que tange aos sistemas meteorológicos, Fedorova \& Carvalho (2000) sustentam o estudo de Kayano \& Sansigolo (2009) quando aqueles analisaram o comportamento de sistemas frontais na América do Sul em um ano de El Niño, um ano de La Niña (julho/1998 a março/1999) e um AN. Destacam que nos meses em que a fase fria do ENOS estava mais intensa a quantidade de dias com frentes frias na faixa de latitudes entre 20 e $40^{\circ} \mathrm{S}$ diminui até $56,7 \%$.

Apesar de serem estimativas de redução na produtividade, essas informações mostram, ao produtor, uma noção da rentabilidade de implantar um sistema de irrigação como forma de minimizar os eventuais malefícios que eventos LN resultam no aumento da demanda de água do milho porém conclusões mais precisas quanto a este argumento são cabíveis a objetivos de estudos futuros.

Como nem sempre o produtor dispõe de infraestrutura para adoção de irrigação, Bergamaschi \& Matzenauer (2009), destacam que se forem implantadas práticas para eliminar o déficit hídrico durante o curto período crítico do milho, sem outras limitações importantes, o produtor poderá assegurar elevados rendimentos a nível de lavoura. Cunha (2001) recomenda o escalonamento de épocas de semeadura com cultivares de diferentes ciclos para evitar a coincidência da seca com o período crítico de toda a lavoura e não utilizar populações de plantas superiores às recomendadas para as condições de baixa precipitação.

Assim e diante do exposto e recorrendo às afirmações previamente destacadas de Bergamaschi et al. (2004; 2006), Bergamaschi \& Matzenauer (2009), em anos LN, se as semeaduras nas principais áreas produtoras de milho em Santa Catarina forem feitas a partir de outubro, as possibilidades de redução na produtividade em decorrência das secas serão minimizadas. Entretanto, Brunini et al. (2001) atentam que os diferentes tipos de solo, com capacidades de retenção de água variada, induzem a um comportamento distinto das cultivares e, em consequência, a diferentes respostas na produtividade.

\section{CONCLUSÕES}

1. Durante anos de La Niña o requerimento de água para irrigação do milho diminui a medida em que as semeaduras são tardadas.

2. O Oeste de Santa Catarina é a região com o maior requerimento de irrigação em anos La Niña, ocorrendo o oposto no município de Major Vieira.

3. As perdas na produtividade do milho decorrentes do déficit hídrico tendem a ser menores para semeaduras feitas a partir de 10 de outubro.

\section{AgradeCimentos}

Os autores agradecem à Empresa de Pesquisa Agropecuária e Extensão Rural de Santa Catarina (EPAGRI) e ao Instituto Nacional de Meteorologia (INMET), pela disponibilidade dos dados meteorológicos.

\section{LITERATURA CITADA}

Adams, R. M.; Houston, L. L.; McCarl, B. A.; Tiscareño, M.; Matus, J.; Weiher, R. F. The benefits to Mexican agriculture of an El Niño-Southern Oscillation (ENSO) early warning system. Agricultural and Forest Meteorology, v.115, p.183194, 2003.

Bergamaschi, H.; Dalmago, G. A.; Bergonci, J. I.; Bianchi, C. A. M.; Müller, A. G.; Comiran, F.; Heckler, B. M. M. Distribuição hídrica no período crítico do milho e produção de grãos. Pesquisa Agropecuária Brasileira, v.39, p.831-839, 2004.

Bergamaschi, H.; Dalmago, G. A.; Comiran, F.; Bergonci, J. I.; Müller, A. G.; França, S.; Santos, A. O.; Radin, B.; Bianchi, C. A. M.; Pereira, P. G. Deficit hídricoe produtividade na cultura do milho. Pesquisa Agropecuária Brasileira, v.41, p.243-249, 2006.

Bergamaschi, H.; Matzenauer, R. Milho. In: Monteiro, J. E. B. A. (ed.) Agrometeorologia dos cultivos: O fator meteorológico na produção agrícola. Brasília: INMET, 2009. Cap.14, p.239-260.

Bergonci, J. I.; Bergamaschi, H.; Santos, A. O.; França, S.; Radin, B. Eficiência da irrigação em rendimento de grãos e matéria seca de milho. Pesquisa Agropecuária Brasileira, v.36, p.949-956, 2001.

Berlato, M. A.; Farenzena, H.; Fontana, D. C. Associação entre El Niño Oscilação Sul e a produtividade do milho no Estado do Rio Grande do Sul. Pesquisa Agropecuária Brasileira, v.40, p.423-432, 2005.

Brunini, O.; Zullo Júnior, J.; Pinto, H. S.; Assad, E.; Sawazaki, E.; Duarte, A. P.; Patterniani, M. E. Z. Riscos climáticos para a cultura de milho no estado de São Paulo. Revista Brasileira de Agrometeorologia, v.9, p.519-526, 2001.

Cardoso, A. O.; Dias, P. L. S. Identificação de trimestres extremos no regime pluviométrico do Sul e Sudeste do Brasil e relação com anomalias da TSM. Revista Brasileira de Meteorologia, v.19, p.149-162, 2004. 
CONAB - Companhia Nacional de Abastecimento. Levantamento de safras. http://www.conab.gov.br. 17 Jan. 2011.

Cruz, G.; Minuzzi, R. B. Influência do fenômeno La Niña na precipitação pluvial na região Oeste de Santa Catarina. Revista Agropecuária Catarinense, v.22, p.85-87, 2009.

Cunha, G. R. El Niño southern oscillation and climate forecasts applied to crops management Southern Brazil. In: Cunha, G. R.; Haas, J. C.; Berlato, M. A. Applications of climate forecasting for better decision-making processes in agriculture. Passo Fundo: Embrapa Trigo, 2001. Cap.9, p.181201.

Doorenbos, J.; Kassam, A. H. Efeito da água no rendimento das culturas. 2.ed. Campina Grande: UFPB, 2000. 221p. Estudos FAO: Irrigação e Drenagem, 33

Doorenbos, J.; Pruitt, W. O. Necessidades hídricas das culturas. Campina Grande: UFPB, 1997. 204p. Estudos FAO: Irrigação e Drenagem, 24

Fang, Q.; Ma, L.; Yu, Q.; Ahujo, L. R.; Malone, R. W.; Hoogenboom, G. Irrigation strategies to improve the water use efficiency of wheat-maize double cropping systems in North China Plain. Agricultural Water Management, v.97, p.1165-1174, 2010.

Fedorova, N.; Carvalho, M. H. de. Processos sinóticos em anos La Niña e El Niño. Parte II: zonas frontais. Revista Brasileira de Meteorologia, v.15, p.57-72, 2000.

Findell, K. L.; Delworth, T. L. Impact of common Sea Surface Temperature anomalies on Global drought and pluvial frequency. Journal of Climate, v.23, p.485-503, 2010.

Grimm, A. M. Variabilidade interanual do clima no Brasil. In: Cavalcanti, I. F. de A.; Ferreira, N. J.; Silva, M. G. A. J. da; Dias, M. A. F. da S. (ed.) Tempo e clima no Brasil. São Paulo: Oficina de Textos, 2009. Cap.22, p.353-374.
Hill, H. S.; Mjelde, J.; Rosenthal, W.; Lamb, P. J. The potential impacts of the use of Southern Oscillation information on the Texas aggregate sorghum production. Journal of Climate, v.12, p.519-530, 1998.

IBGE - Instituto Brasileiro de Geografia e Estatística. Banco de dados agregados SIDRA. (http://www.sidra.ibge.gov.br). 30 Out. 2011.

Kayano, M. T.; Sansigolo, C. Interannual and decadal variations of precipitation and daily maximum and daily minimum temperatures in southern Brazil. Theoretical and Application Climatology, v.97, p.81-90, 2009.

Legler, D. M.; Bryant, K. J.; O’Brien, J. J.. Impact of ENSO related climate anomalies on crop yields in the U.S. Climatic Change, v.42, p.351-375, 1999.

Marouelli, W. A.; Silva, W. L. de C.; Silva, H. R. da. Irrigação por aspersão em hortaliças: Qualidade da água, aspectos do sistema e método prático de manejo. 2.ed. Brasília: Embrapa Informação Tecnológica, 2008. 150p.

Matzenauer, R.; Bergamaschi, H.; Berlato, M. A. Evapotranspiração da cultura do milho. II - Relações com a evaporação do tanque Classe "A", com a evapotranspiração de referência e com a radiação solar global, em três épocas de semeadura. Revista Brasileira de Agrometeorologia, v.6, p.15-21, 1998.

Minuzzi, R. B. Chuvas em Santa Catarina durante eventos do El Niño Oscilação Sul. Revista Geosul, v.25, p.107-127, 2010.

Phillips, J. G.; Cane, M. A.; Rosenzweig, C. ENSO, seasonal rainfall patterns and simulated maize yield varibility in Zimbabwe. Agricultural and Forest Meteorology, v.90, p.3950, 1998.

Travasso, M. I.; Magrin, G. O.; Grondona, M. O.; Rodriguez, G. R. The use of SST and SOI anomalies as indicators of crop yield variability. International Journal of Climatology, v.29, p.23-29, 2009. 